American Journal of Pharmacology and Toxicology 5 (2): 112-118, 2010

ISSN 1557-4962

(C) 2010 Science Publications

\title{
The Effects of W7, a Specific Calmodulin Inhibitor, to the Antinociceptive Effects of Morphine in Adrenalectomized Rats
}

\author{
${ }^{1}$ Gholamreza Sepehri, ${ }^{1}$ Kayvan Yaghoobi, ${ }^{1}$ Vahid Sheibani, \\ ${ }^{2}$ Ali Shamsizadeh and ${ }^{3}$ Mohammad Khaksari \\ ${ }^{1}$ Neuroscience Research Center, Department of Physiology and Pharmacology, \\ Kerman University of Medical Sciences, Kerman, Iran \\ ${ }^{2}$ Department of Physiology, Rafsanjan University of Medical Sciences, Rafsanjan, Iran \\ ${ }^{3}$ Physiology Research Center, Department of Physiology and Pharmacology, \\ Kerman University of Medical Sciences, Kerman, Iran
}

\begin{abstract}
Problem statement: This study was performed to evaluate the effect of W7 (specific calmodulin inhibitor) on morphine induced analgesia in Adrenalectomized (ADX) rats by tail-flick test. Approach: Tolerance to morphine was induced in male Wistar rats by daily injections of morphine (15 mg kg-1, i.p) for 8 days. Adrenalectomy was performed under general anesthesia with intraperitoneal (i.p) injection of ketamine $\left(50 \mathrm{mg} \mathrm{kg}^{-1}\right)$ and xylazine $\left(5 \mathrm{mg} \mathrm{kg}^{-1}\right)$. In sham operated animals only the incision was made but adrenals were not removed. Five days after surgery, W7 (0.25,

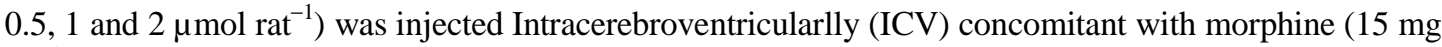
$\mathrm{kg}^{-1}$, i.p) for 8 consecutive days. Tail Flick Latency (TFL) was used to assess the nociceptive response at days 1, 3, 5 and 8 before and 30 min after morphine administration in sham operated and ADX rats. Maximal Possible Effect percentage (MPE \%) was considered as analgesia index. Results: The results showed that daily morphine injection caused a marked analgesia in rats, but MPE \% decreased significantly after 8 days which shows the development of tolerance to morphine $(\mathrm{p}<0.05)$. MPE \% following morphine treatment in ADX rats was significantly greater than sham operated rats $(\mathrm{p}<0.05)$ and $\mathrm{W} 7(0.5,1$ and $2 \mathrm{micromol} / \mathrm{rat} / \mathrm{ICV})$ significantly attenuated the development of tolerance to morphine in $\mathrm{ADX}$ rats compared to sham operated rats $(\mathrm{p}<0.05$ and $\mathrm{p}<0.001)$. Corticosterone replacement reversed the effect of $\mathrm{W} 7$ on ADX rats $(\mathrm{p}<0.005)$. Conclusion: The results of this study showed that hypothalamic- pituitary-adrenal axis and calmodulin may play a role in the development of tolerance to morphine antinociceptive effects in rats.
\end{abstract}

Key words: Morphine, analgesia, W7, calmodulin inhibitor, adrenalectomy

\section{INTRODUCTION}

Opiates addiction is a phenomenon with complex physiological and social cause and consequences (Nestler, 1997; 2004). Drug tolerance invariably develops in almost all chronic pain patients who receive opioids. The development of drug tolerance will necessitate higher doses of the same drug or use of a more efficacious opioid drug, which leads to exacerbated adverse effects including respiratory depression, cognitive changes and increased vulnerability to drug dependence. In some cases, even the highest tolerable dose of an opioid drug cannot achieve the desirable analgesic effect in patients (Nestler, 2004; Barria et al., 1997; Lefkowitz, 1998;
Hamdy et al., 2004; Cai et al., 1997; Gainetdinov et al., 2004). The molecular mechanism underlying opioid tolerance is not entirely understood. N-Methyl-DAspartate (NMDA) receptor is a key component in promoting opioid tolerance (Cai et al., 1997). Calcium ions are thought to play an important role in many cellular processes. Calmodulin is a major $\mathrm{Ca}^{2+}$ - binding protein found in the central nervous system and is involved in a variety of cellular functions through the activation of Calmodulin-Dependent enzymes, such as adenylate cyclase, phosphodiesterases, protein kinases, $\mathrm{Ca}^{2+} /$ calmodulin-dependent protein Kinases (CaMK) and $\mathrm{Ca}^{2+} /$ calmodulin-dependent nitric oxide synthase, mitogenactivated protein kinase and so on. It also regulates the activities of the plasma membrane $\mathrm{Ca}^{2+}$

Corresponding Author: Gholamreza Sepehri, Neuroscience Research Center, Department of Physiology and Pharmacology, Kerman University of Medical Sciences, Kerman, Iran Tel: +98- 3413220081 Fax: +98- 341- 3220081 
pump and various ion channels and neurotransmitter release (Cheung, 1982).

Increasing evidence indicates that $\mathrm{Ca}^{2+} /$ calmodulin plays a role in opiate tolerance and dependence. It is reported that the increase in opiate receptor density after treatment with opiate antagonists is accompanied by increased amounts of membrane-bound calmodulin, which suggests that opiate receptors and calmodulin share common regulatory systems (Baram and Simantov, 1983). It has been suggested that during chronic opioid exposure, calmodulin in the thalamus may account for the efficacy of the phenothiazines in controlling withdrawal phenomena by binding to calmodulin and has a potentially significant role in the biological basis of physical dependence on opioids (Hamdy et al., 2004; Bonnet et al., 1982).

ADX potentiates morphine analgesia through both mechanisms of increased morphine content and the increased sensitivity to morphine and that the lack of glucocorticoids participates in both of these ADXinduced effects (Miyamoto et al., 1990). Other studies suggest that corticosterone plays an important role in determining the diurnal rhythm of opiate- induced feeding and the function of endogenous opioids in the regulation of energy balance (Bhakthavatsalam and Leibowitz, 1986).

Since the role of Hypothalamic-Pituitary-Adrenal (HPA) axis in the development of tolerance to the antinociceptive effects of morphine has not been elucidated yet, so this study was performed to evaluate the effect of W7 (specific Calmodulin inhibitor) on morphine induced analgesia in ADX rats by tail-flick test.

\section{MATERIALS AND METHODS}

Animals: All experiments were carried out on male Wistar rats, weighing 200-250 g, that were housed four per cage under a $12 \mathrm{~h}$ light/dark cycle in a room with controlled temperature $\left(22 \pm 1^{\circ} \mathrm{C}\right)$. Food and water were available ad libitum except in Adrenalectomized (ADX) rats. Animals were handled daily (between 9:00 and 10:00 am) for 5 days before the experiment day in order to adapt them to manipulation and minimize nonspecific stress responses. Rats were divided randomly into several experimental groups, each comprising 6-10 animals. All of the procedures were in accordance with guidelines for caring and using of laboratory animals in Neuroscience Research Center of Kerman University of Medical Sciences and the European Communities Council Directive of 24 November 1986 (86/609/EEC).
Drugs: Morphine hydrochloride was dissolved in saline and W7 (Allexis, USA) was dissolved in Dimethyl Sulfoxide (DMSO) plus saline. These drugs were given in the volume of $1 \mathrm{ml} \mathrm{kg}^{-1}$, i.p. Corticosterone (LKT Laboratories, Germany) was dissolved in absolute ethanol and then dissolved in $0.9 \%$ sodium chloride solution, yielding final concentration of $100 \mu \mathrm{g} \mathrm{mL}^{-1}$ of drinking solution.

Morphine tolerance: To induce tolerance to analgesic effect, morphine was given chronically in a daily dose of $15 \mathrm{mg} \mathrm{kg}^{-1}$ day for 8 days. W-7 or DMSO was given according to the same schedule as control groups. Antinociception was assessed by tail-flick test. Antinociceptive test was performed both before and 30 min after drug administration in days $1,3,5$ and 8 . To determine the effect of $\mathrm{W}-7$ on the development of morphine tolerance, $\mathrm{W}-7\left(0.25,0.5,1\right.$ and $\left.2 \mu \mathrm{mol} \mathrm{rat}^{-1}\right)$ was given concomitant with morphine but in days that nociceptive testing was measured, morphine was injected first and antinociception was measured $30 \mathrm{~min}$ after drug administration and then, W-7 was injected. Control animals received saline using the same time course.

Antinociceptive test: Antinociception was assessed by tail-flick test. Radiant heat was applied at 5-8 cm from the tip of the tail using a tail-flick apparatus (PANLAB 7160, Spain). Tail Flick Latency (TFL) was measured as the time of the beam exposure to the withdrawal time of the tail. The mean of three consecutive TFL was measured at 1-min intervals before drug or solvent administration (basal latency) and then similar TFL was measured at specific times after drug or solvent administration, (experimental latencies) (Mahani et al., 2005). The intensity of radiant heat was adjusted to establish the basal latency of 3-5 sec. To avoid tissue damage, a cut-off time of $15 \mathrm{sec}$ was set. Trials were automatically terminated if a response did not occur within $15 \mathrm{sec}$ (Doi et al., 1988). Maximal Possible Effect percentage (MPE \%) was considered as analgesia index which was calculated by the following formula:

Antinociception $(\%)=\frac{\left(\begin{array}{l}\text { Experimental latency }- \\ \text { Basal }(\% \text { MPE }) \text { latency }\end{array}\right)}{(15-\text { Basal latency })} \times 100$

Adrenalectomy: Animals were anesthetized with intraperitoneal (i.p) injection of ketamine $\left(50 \mathrm{mg} \mathrm{kg}^{-1}\right)$ and xylazine $\left(5 \mathrm{mg} \mathrm{kg}{ }^{-1}\right)$. Both adrenal glands were removed through two dorsal incisions. The sham operation consisted of bilateral dorsal incision, plus 
locating and exposing the adrenals. All Adrenalectomized (ADX) rats were maintained on $0.9 \% \mathrm{NaCl}$ drinking solution, whereas the sham operated rats were kept on tap water. The animals were tested 5 days after the adrenalectomy or sham procedure.

Stereotaxic surgery: Rats were anesthetized with ketamine (100 $\mathrm{mg} \mathrm{kg}^{-1}$, i.p.) and unilateral stainlesssteel guide cannulas were stereotaxicaly implanted. The cannulas were implanted with the bregma taken as origin for coordinates: A $-0.8, \mathrm{Ll}+1.6, \mathrm{~V}-3.7$ from the skull.

Corticosterone replacement: For corticosterone replacement in adrenalectomized rats, corticosterone was dissolved in $2 \mathrm{~mL}$ of ethyl alcohol and then dissolved in $0.9 \%$ sodium chloride solution, yielding final concentration of $100 \mu \mathrm{g} \mathrm{mL}^{-1}$ of drinking solution (continuously from the time of ADX). The amount of drinking solution consumed by each rat was analyzed to determine whether there were any group differences. At the end of experimental days, rats were sacrificed with decapitation between 9:00-10:00 am and trunk blood was collected into tubes containing 5\% EDTA and plasma corticosterone was measured by Radioimmunoassay (RIA) using a commercial kit for rats $\left(\left[{ }^{125} \mathrm{I}\right]\right.$ corticosterone, DRG International, Inc. USA).

Statistical analysis: The results are expressed as mean \pm SEM. The difference in MPE \% (antinociception) and corticosterone levels between groups over the time course of study was determined by two or one-way Analysis Of Variance (ANOVA), respectively followed by the Tukey post hoc test with $5 \%$ level of significance $(\mathrm{p}<0.05)$. For accessing tail flick latencies or \%MPE in one group for several days we used repeated measure test and to determine the cause of difference used one sample t-test and for reducing error we used Bonferroni Adjustment.

\section{RESULTS}

The effect of adrenalectomy and corticosterone replacement on the levels of plasma corticosterone: As shown in the Table 1, plasma corticosterone concentrations were significantly reduced in ADX $\left(21.4 \pm 2 \mathrm{ng} \mathrm{mL}^{-1}\right) \quad$ compared with control $\left(220.3 \pm 24 \mathrm{ng} \mathrm{mL}^{-1}\right)$ and sham operated animals $\left(225 \pm 20 \mathrm{ng} \mathrm{mL} \mathrm{m}^{-1}\right)$. In ADX animals that had corticosterone replaced in their drinking water $(\mathrm{ADX}+\mathrm{CORT})$, the plasma corticosterone concentration
(177 $\pm 33 \mathrm{ng} \mathrm{mL} \mathrm{m}^{-1}$ ) was not significantly different from control animals $\left(220.3 \pm 24 \mathrm{ng} \mathrm{mL}{ }^{-1}\right)(\mathrm{p}>0.05)$. In this group (ADX+CORT) plasma corticosterone concentrations were similar during different days of testing (data is not shown).

Table 1: Plasma corticosterone level in normal, sham operated, ADX and ADX rats received corticosterone replacement therapy

\begin{tabular}{lc} 
& Plasma corticosterone concentration $\left(\mathrm{ng} \mathrm{L}^{-1}\right)$ \\
\hline Control & $220.3 \pm 24$ \\
Sham & $225.0 \pm 20$ \\
ADX & $21.4 \pm 2 *$ \\
ADX + CORT & $177.0 \pm 33$ \\
\hline
\end{tabular}

Values represent mean \pm SEM of at least 6 rats in each group; ADX: Adrenalectomy; COTR: Corticosterone; *: p<0.001: ADX rats compared to normal, sham and $\mathrm{ADX}+\mathrm{CORT}$ group

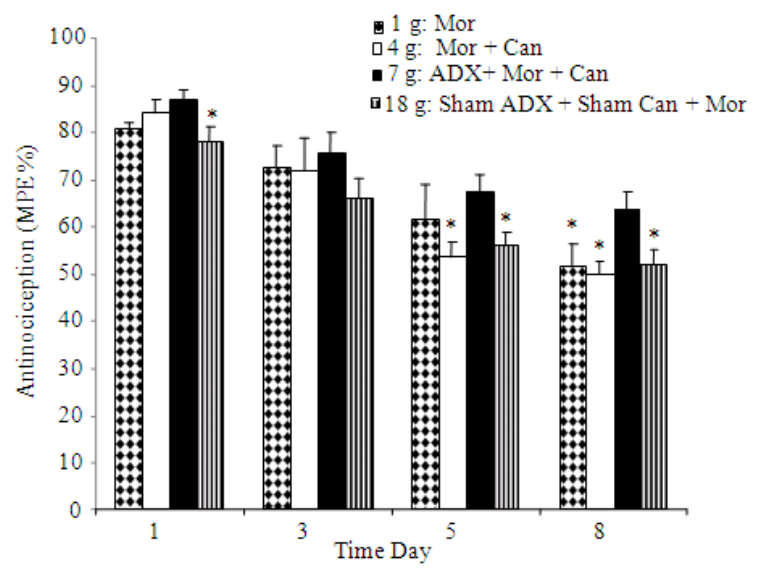

Fig. 1: Maximal Possible Effect (MPE) percentage to morphine (15 mg kg-1 day $^{-1}$ for 8 days) in cannlated, adrenalectomized and sham operated rats. Tail flick response was measured before and $30 \mathrm{~min}$ after morphine administration on days $1,3,5$ and 8 . Values represent mean \pm SEM of at least 6 rats in each group. Chronic morphine administration (15 mg kg-1 day $^{-1}$, i.p/8 days) induced tolerance to its antinociceptive effect; MPE \% on the fifth and eighth days were significantly reduced compared with MPE \% on the first day $(\mathrm{p}<0.05)$. MPE \% in adrenalectomized rats is significantly higher than sham operated rats at 5th and 8th days after morphine treatment ( $<<0.05)$. ADX: Adrenalectomy; Can: Cannula; Mor: Morphine, MPE: Maximal Possible Effect; *: $p<0.05$

Development of tolerance to morphine-induced analgesia: Figure 1 shows that tolerance to the analgesic response of morphine was induced in control, 
cannulated, Adrenalectomized (ADX) and sham operated rats. As the Fig. 1 shows there was no significant difference in the Maximal Possible Effect (MPE \%) following morphine treatment in control, cannulated and sham operated rats, however, dailymorphine injection for 8 day caused a significant tolerance to the analgesic response to morphine injection and the MPE \% 8 days after morphine injection was significantly lower than the first day $(\mathrm{p}<0.05)$. Also there was a significant difference in antinociceptive response between ADX rats and sham operated, cannulated and control rats and MPE \% following morphine treatment in $\mathrm{ADX}$ rats was significantly greater than sham operated rats $(\mathrm{p}<0.05)$ (Fig. 1).

Effect of ICV injection of W-7 on the development of tolerance to analgesic effect of morphine in Adrenalectomized (ADX) rats ICV injection of various doses of W-7 alone did not affect the Maximal Possible Effect percentage (MPE \%) compared with ADX group ( $\mathrm{p}>0.05)$ (data not shown).

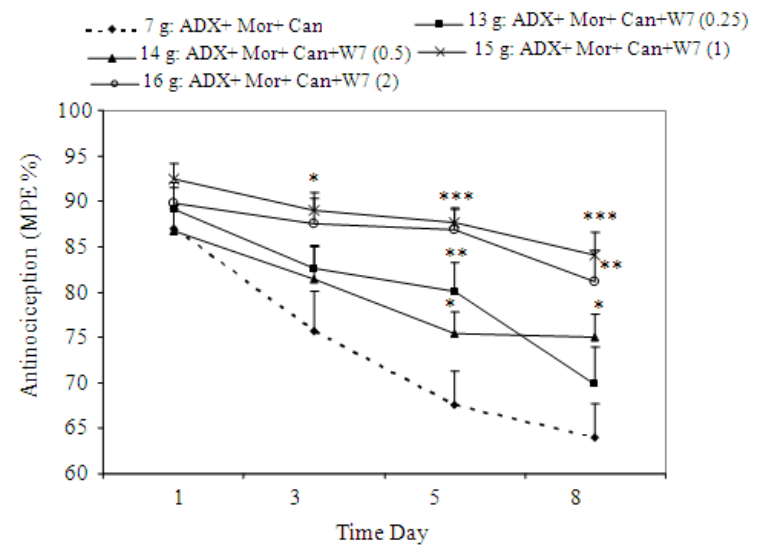

Fig. 2: The effect of ICV injection of W-7 $(0.25,0.5,1$

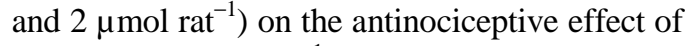
morphine (15 $\mathrm{mg} \mathrm{kg}^{-1}$, i.p/8 days) in ADX rats. $\mathrm{W}-7$ was injected $10 \mathrm{~min}$ prior to morphine injection and tail flick response was measured before and 30, 60, 90 and $120 \mathrm{~min}$ after morphine administration. W-7 and DMSO were injected intracerebroventricularly and morphine and saline were injected intraperitonealy. Values represent mean \pm SEM of at least 6 rats in each group. ADX: Adrenalectomy; Can: Cannula; Mor: Morphine, MPE: Maximal Possible Effect; *: $\mathrm{p}<0.05$ Morphine $+\mathrm{W}-7$ compared to morphine treated group; $* *: \mathrm{p}<0.005$ Morphine + W-7 compared to morphine treated group; ***: $\mathrm{p}<0.001$ Morphine $+\mathrm{W}-7$ compared to morphine treated group
However, ICV injection of $\mathrm{W}-7$ attenuated the development of tolerance to analgesic effect of morphine in a dose dependent manner, i.e., MPE \% on day 3,5 and 8 in rats receiving morphine $+\mathrm{W}-7(0.5,1$ and 2 micromol rat $^{-1}$ ) showed a significant increase compared with that of morphine + DMSO-treated rats $(p<0.05$ and $p<0.001)$ which means that chronic ICV administration of $\mathrm{W}-7$ effectively attenuated the development of morphine tolerance (Fig. 2). However, corticosterone replacement reversed the effect of W7 on ADX rats and chronic morphine injection for 8 days caused significant reduction in the MPE \% in the same manner as the sham operated rats $(\mathrm{p}<0.005)$, (Fig. 3). Also plasma corticosterone level $\left(177.3 \pm 33.7 \mathrm{ng} \mathrm{mL}^{-1}\right)$ was close to the control $\left(220.3 \pm 24 \mathrm{ng} \mathrm{mL}^{-1}\right)$ and sham operated $225 \pm 20 \mathrm{ng} \mathrm{mL} \mathrm{mL}^{-1}$ ) rats which shows no significant difference (Table 1).

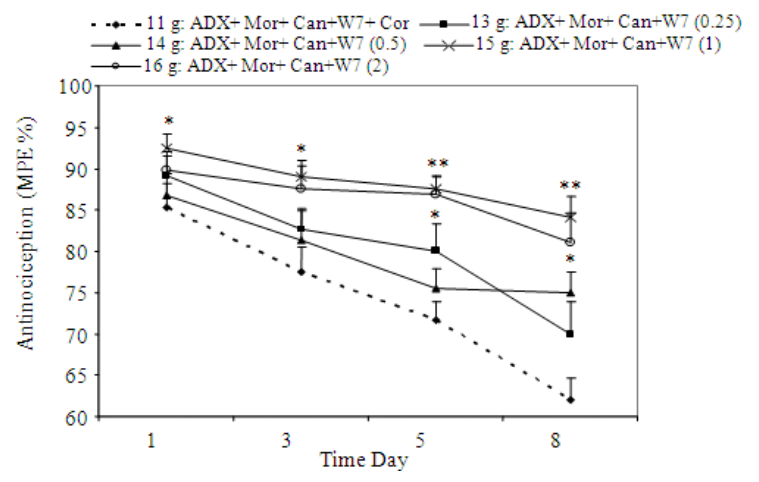

Fig. 3: The effect of corticosterone replacement therapy and ICV injection of $\mathrm{W}-7(0.25,0.5,1$

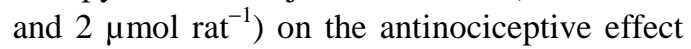
of morphine (15 mg kg-1, i.p/8 days) in ADX rats. W-7 was injected $10 \mathrm{~min}$ prior to morphine injection and tail flick response was measured before and 30, 60, 90 and $120 \mathrm{~min}$ after morphine administration. Corticosterone was dissolved in $2 \mathrm{~mL}$ of ethyl alcohol and then combined with $0.9 \% \mathrm{NaCl}$, yielding final concentration of $100 \mathrm{Ag} \mathrm{mL}^{-1}$ of drinking solution (continuously from the time of ADX). W-7 and DMSO were injected intracerebroventricularly and morphine and saline were injected intraperitonealy. Values represent mean \pm SEM of at least 6 rats in each group. ADX: Adrenalectomy; Can: Cannula; Mor: morphine; MPE: Maximal Possible Effect; *: $\mathrm{p}$ <0.05: Morphine $+\mathrm{W}-7$ compared to morphine + Corticosterone replacement group; **: $\mathrm{p}<0.001:$ Morphine $+\mathrm{W}-7$ compared to morphine + Corticosterone replacement group 


\section{DISCUSSION}

The results of this study showed that administration of morphine alone for 8 days induced tolerance to its antinociceptive effect and the MPE \% reduced significantly in all morphine treated groups (all $\mathrm{p}<0.05)$. Also antinociceptive response to morphine showed that adrenalectomy could attenuate the tolerance development to morphine antinociception and the analgesic response to morphine was increased in ADX rats as compared to sham operated rats $(\mathrm{p}<0.05)$ (Fig. 1).

The results of this study are in complete agreement with other previous reports that ADX could potentiates morphine analgesia through both mechanisms of increased morphine content and the increased sensitivity to morphine and that the lack of glucocorticoids participates in both of these ADXinduced effects (Miyamoto et al., 1990). Other studies suggest that corticosterone plays an important role in determining the diurnal rhythm of opiate- induced feeding and the function of endogenous opioids in the regulation of energy balance (Bhakthavatsalam and Leibowitz, 1986).

Also our data showed that ICV injection of W-7 attenuated the development of tolerance to the analgesic effect of morphine in a dose dependent manner, which means that chronic ICV administration of W-7 effectively attenuated the development of morphine tolerance (Fig. 2). However, corticosterone replacement reversed the effect of $\mathrm{W} 7$ on $\mathrm{ADX}$ rats and chronic morphine injection.

Calmodulin is a major $\mathrm{Ca}^{2+}$-binding protein found in the central nervous system and is involved in a variety of cellular functions through the activation of calmodulin-dependent enzymes, such as adenylate cyclase, phosphodiesterases, protein kinases, $\mathrm{Ca}^{2+} /$ Calmodulin-dependent Protein Kinases (CaMK) and $\mathrm{Ca}^{2+} /$ calmodulin-dependent nitric oxide synthase, mitogenactivated protein kinase and so on. It also regulates the activities of the plasma membrane $\mathrm{Ca}^{2+}$ pump and various ion channels and neurotransmitter release and many of these enzyme are involved in the morphine analgesia and tolerance (Cheung, 1982).

The precise mechanism (s) by which calmodulin may be involved in the morphine tolerance is not determined yet, but other studies reported that calmodulin is involved in the process of tolerance to opioids (Fan et al., 1999; Liang et al., 2004; Lou et al., 1999; Nehmad et al., 1982; Niu et al., 2000; Tang et al., 2006; Wang et al., 1999; Ye et al., 2004). There is a close relationship between opioid receptors and $\mathrm{Ca}^{2+} /$ calmodulin signal transduction pathways.
Calmodulin is also involved in opioid receptor signal transduction as a possible second messenger (Ye et al., 2004). Wang et al. (1999) have shown that calmodulin binds directly to the opioid receptor and is released from the plasma membrane on receptor agonist stimulation (Wang et al., 1999). Others reported that calmodulin may facilitate CaMKII activation in opioid stimulated cells (Wang et al., 1999) and intraventricular application of CaMKII inhibitors has been shown to inhibit morphine tolerance and dependence (Fan et al., 1999) Extensive evidence suggests that, at the cell and molecular level, CaMKII is involved in opioid receptor function and its signal transduction (Cai et al., 1997; Lou et al., 1999).

Also it has been shown that calmodulin content and location changed during chronic morphine administration. It is reported that chronic morphine treatment increased calmodulin contents in the rat's brain (Nehmad et al., 1982). Moreover, the intracellular calcium elevation by opioid receptor stimulation (Diaz et al., 1995; Welch and Olson, 1991) leads to calmodulin dissociation from cell membrane (Fan et al., 1999). The increase in cytosolic calmodulin prompts the translocation of calmodulin into the nucleus (Wang et al., 2000) which regulates the gene expression by morphine (Niu et al., 2000; Deisseroth et al., 1998). Also it has been reported that chronic treatments with opioids increases $\mathrm{Ca}^{2+} /$ calumodulin activity (Nehmad et al., 1982) and mRNA levels (Niu et al., 2000). Indeed, expression and activation of CaMKII $\alpha$ are both increased in opioid tolerance (Liang et al., 2004; Lou et al., 1999; Tang et al., 2006; Wang et al., 2003).

\section{CONCLUSION}

In summary, our results indicated that chronic inhibition of calmodulin activity by ICV injection of its specific inhibitor, W-7, attenuated morphine tolerance in a dose dependent manner as evidenced by a significant increased in the Maximal Possible Effect (MPE \%) on day 5 and 8 in ADX rats as compared to sham operated rats. Further studies need to be carried out to better understand the underlying mechanism (s) of these findings and determine the relevance of them in human.

\section{ACKNOWLEDGMENT}

This study was supported by a grant from Neuroscience Research Center, Kerman University of Medical Sciences, Kerman, Iran. 


\section{REFERENCES}

Baram, D. and R. Simantov, 1983. Enkephalins and opiate antagonists control calmodulin distribution in neuroblastoma-glioma cells. J. Neurochem., 40: 55-63. PMID: 6294249

Barria, A., D. Muller, V. Derkach, L.C. Griffith and T.R. Soderling, 1997. Regulatory phosphorylation of AMPA-type glutamate receptors by CaM-KII during long-term potentiation. Science, 276: 2042-2045. DOI: 10.1126/science.276.5321.2042

Bhakthavatsalam, P. and S.F. Leibowitz, 1986. Morphine-elicited feeding: Diurnal rhythm, circulating corticosterone and macronutrient selection. Pharmacol. Biochem. Behav., 24: 911-917. PMID: 3012600

Bonnet, K.A., L. Engelberg and S.A. Gusik, 1982. Calmodulin increases in selective brain regions with opioid dependence. Life Sci., 31: 2295-2298. PMID: 6298523

Cai, Y.C., L. Ma, G.H. Fan, J. Zhao and L.Z. Jiang et al., 1997. Activation of N-methyl-D-aspartate receptor attenuates acute responsiveness of delta-opioid receptors. Mol. Pharmacol., 51: 583-587. PMID: 9106622

Cheung, W.Y., 1982. Calmodulin: An overview. Fed. Proc., 41: 2253-2257. PMID: 6281080

Deisseroth, K., E.K. Heist and R.W. Tsien, 1998. Translocation of calmodulin to the nucleus supports CREB phosphorylation in hippocampal neurons. Lett. Nat., 392: 198-202. DOI: $10.1038 / 32448$

Diaz, A., F. Ruiz, J. Florez, A. Pazos and M.A. Hurle, 1995. Regulation of dihydropyridine-sensitive $\mathrm{Ca}^{++}$ channels during opioid tolerance and supersensitivity in rats. J. Pharmacol. Exp. Ther., 274: 1538-1544. PMID: 7562531

Doi, T., S. Kuzuna and M. Fujino, 1988. Study on the receptor subtypes mediating the analgesic action of an enkephalin analog, Tyr-D-Met(O)-Gly-EtPhe$\mathrm{NHNHCOCH}_{3}$.AcOH (EK-399). Jap. J. Pharmacol., 47: 409-415. DOI: 10.1254/jjp.47.409

Fan, G.H., L.Z. Wang, H.C. Qiu, L. Ma and G. Pei, 1999. Inhibition of calcium/calmodulin-dependent protein kinase II in rat hippocampus attenuates morphine tolerance and dependence. Mol. Pharmacol., 56: 39-45. PMID: 10385682

Gainetdinov, R.R.,R.T.Premont, L.M. Bohn, R.J. Lefkowitz and M.G. Caron, 2004. Desensitization of G protein-coupled receptors and neuronal functions. Annu. Rev. Neurosci., 27: 107-144. DOI: 10.1146/annurev.neuro.27.070203.144206
Hamdy, M.M., Y. Noda, M. Miyazaki, T. Mamiya and A. Nozaki et al., 2004. Molecular mechanisms in dizocilpine-induced attenuation of development of morphine dependence: An association with cortical $\mathrm{Ca}^{2+} /$ calmodulin-dependent signal cascade. Behav. Brain Res., 152: 263-270. DOI: 10.1016/j.bbr.2003.10.014

Lefkowitz, R.J., 1998. G protein-coupled receptors. III. New roles for receptor kinases and $\beta$-arrestins in receptor signaling and desensitization. J. Biol. Chem., 273: 18677-18680. DOI: 10.1074/jbc.273.30.18677

Liang, D., X. Li and J.D. Clark, 2004. Increased expression of $\mathrm{Ca}^{2+} /$ calmodulin-dependent protein kinase II alpha during chronic morphine exposure. Neuroscience, 123: 769-775. DOI: 10.1016/j.neuroscience.2003.10.007

Lou, L., T. Zhou, P. Wang and G. Pei, 1999. Modulation of $\mathrm{Ca}^{2}+/$ calmodulin-dependent protein kinase II activity by acute and chronic morphine administration in rat hippocampus: Differential regulation of alpha and beta isoforms. Mol. Pharmacol., 55: 557-563. PMID: 10051541

Mahani, S.E., F. Motamedi, M. Javan and A. Ahmadiani, 2005. Involvement of hypothalamic pituitary adrenal axis on the effects of nifedipine in the development of morphine tolerance in rats. Pharmacol. Biochem. Behav., 81: 152-157. DOI: 10.1016/j.pbb.2005.03.004

Miyamoto, Y., M. Ozaki, S. Kishioka, T. Yamanishi and Y. Kitabata et al., 1990. Adrenalectomyinduced potentiation of morphine analgesia: Reversal by prednisolone. Pharmacol. Biochem. Behav., 37: 703-706. PMID: 2093175

Nehmad, R., H. Nadler and R. Simantov, 1982. Effects of acute and chronic morphine treatment of calmodulin activity of rat brain. Mol. Pharmacol., 22: 389-394. PMID: 6128669

Nestler, E.J., 1997. Molecular mechanisms of opiate and cocaine addiction. Curr. Opin. Neurobiol., 7: 713-719. DOI: 10.1016/S0959-4388(97)80094-3

Nestler, E.J., 2004. Molecular mechanisms of drug addiction. Neuropharmacology, 1: 24-32. DOI: 10.1016/j.neuropharm.2004.06.031

Niu, S., C.H. Kuo, Y. Gan, E. Nishikawa and T. Sadakata et al., 2000. Increase of calmodulin III gene expression by $\mu$-opioid receptor stimulation in PC12 cells. Jap. J. Pharmacol., 84: 412-417. DOI: 10.1254/jjp.84.412

Tang, L., P.K. Shukla and Z.J. Wang, 2006. Trifluoperazine, an orally available clinically used drug, disrupts opioid antinociceptive tolerance. Neurosci. Lett., 397: 1-4. PMID: 16380209 
Wang, D., W. Sadee and J.M. Quillan, 1999. Calmodulin binding to $\mathrm{G}$ protein-coupling domain of opioid receptors. J. Biol. Chem., 274: 22081-22088. DOI: $10.1074 / \mathrm{jbc} .274 .31 .22081$

Wang, D., L.M. Tolbert, K.W. Carlson and W. Sadee, 2000. Nuclear $\mathrm{Ca}^{2+} /$ calmodulin translocation activated by $\mu$-opioid $\left(\mathrm{OP}_{3}\right)$ receptor. J. Neurochem., 74: 1418-1425. DOI: 10.1046/j.14714159.2000.0741418.x

Wang, Z.J., L. Tang and L. Xin, 2003. Reversal of morphine antinociceptive tolerance by acute spinal inhibition of $\mathrm{Ca}^{2+} /$ calmodulin-dependent protein kinase II. Eur. J. Pharmacol., 465: 199-200. DOI: 10.1016/S0014-2999(03)01484-5
Welch, S.P. and K.G. Olson, 1991. Opiate toleranceinduced modulation of free intracellular calcium in synaptosomes. Life Sci., 48: 1853-1861. PMID: 1710309

Ye, X.F., Y. Lu, P. Zhang and J.H. Liang, 2004. Calmodulin inhibitor trifluoperazine attenuates the development and expression of morphine-induced conditioned place preference in rats. Eur. J. Pharmacol., 486: 265-271. PMID: 14985048 